\title{
Juan Antonio Moldes: De criado a comerciante global y funcionario regio (Salta, Buenos Aires, Cádiz, Filipinas, 1764-1804)*
}

\author{
por \\ María Fernanda Justiniano, Carina Madregal y Gabriel Anachuri ${ }^{1}$ \\ Universidad Nacional de Salta, Salta, Argentina
}

Formadores de opinión y estudiosos de lo social favorecieron la construcción de principios diferenciadores en la flamante sociedad salteña independiente. Los enfoques global y relacional proporcionan un utillaje teórico y metodológico que permiten superar los límites interpretativos del nacionalismo metodológico cargado de supuestos eurocéntricos.

Este artículo se propone deconstruir esta operación ideológica y mostrar a través del estudio de Juan Antonio Moldes, las posibilidades de ascenso social que cupieron en el interior de la Monarquía hispánica y en la Intendencia de Salta del Tucumán.

Moldes fue un criado gallego que, a través de las actividades del préstamo y el tejido de una red comercial de nivel global que abarcó Salta, Buenos Aires, Cádiz, Filipinas, La Paz y Potosí, pudo enriquecerse y promocionar social, política y económicamente en la sociedad que le cobijó.

PALABRAS ClaVE: historia económica; historia argentina; historia regional; historia de Salta.

Cómo Citar este artículo / Citation: Justiniano, María Fernanda, Madregal, Carina y Anachuri, Gabriel, "Juan Antonio Moldes: De criado a comerciante global y funcionario regio (Salta, Buenos Aires, Cádiz, Filipinas, 1764-1804)", Revista de Indias, LXXIX/276 (Madrid, 2019): 433-457. https://doi.org/10.3989/revindias.2019.013.

* Este artículo es fruto del dictado del «Seminario Salta y la Nación en el siglo XIX. Transformaciones políticas, económicas, sociales y fiscales» y del Proyecto de Investigación $\mathrm{N}^{\circ} 2340$ del Consejo de Investigación de la Universidad Nacional de Salta.

Agradecemos a los evaluadores el tiempo invertido y la pertinencia de las sugerencias para mejorar el escrito. Todo error del texto es responsabilidad nuestra.

1 mafernandajustiniano@yahoo.com.ar, ORCID iD: https://orcid.org/0000-0002-0965-3281. carina.m2401@gmail.com, ORCID iD: https://orcid.org/0000-0001-8688-3542.

gabrielanachuri2016@gmail.com, ORCID iD: https://orcid.org/0000-0002-4127-2665.

Copyright: (C) 2019 CSIC. Este es un artículo de acceso abierto distribuido bajo los términos de una licencia de uso y distribución Creative Commons Reconocimiento 4.0 Internacional (CC BY 4.0). 
Tras los procesos independentistas las historiografías locales de la Argentina decimonónica iniciaron un proceso de legitimación de las nuevas elites gobernantes de la novísima república. Formadores de opinión y estudiosos de lo social favorecieron la construcción de principios diferenciadores en la flamante sociedad salteña independiente decimonónica.

Este artículo se propone deconstruir tal operación ideológica y mostrar, a través del estudio de la trayectoria Juan Antonio Moldes, las posibilidades de ascenso social que cupieron en el interior de la Monarquía hispánica y en la Intendencia de Salta del Tucumán.

Los enfoques, global y relacional, proporcionan el utillaje teórico y metodológico que permite superar los límites interpretativos del nacionalismo metodológico cargado de supuestos eurocéntricos ${ }^{2}$. El análisis se nutre de fuentes existentes en repositorios globales, que no fueron consultadas, y que hoy contribuyen a este cambio de perspectiva.

Juan Antonio Moldes fue un criado gallego que llegó a Salta a mediados del siglo XVIII. A través de las actividades del préstamo y el tejido de una red comercial de nivel global, que abarcó Salta, Buenos Aires, Cádiz, Filipinas, La Paz, Potosí, pudo enriquecerse y ubicarse social, política y económicamente en la sociedad que lo cobijó. De él y su descendencia, poco se indagó y mucho se dijo y escribió. Al tiempo del fallecimiento del patriarca de la familia, en 1807, los hijos hubieron desplegado fortuna e influencia a ambos lados del Atlántico; y en el mundo monárquico y en el independiente.

Cuando la independencia y el igualitarismo desencadenados en estos territorios americanos desarticularon los sólidos principios diferenciadores construidos en tiempos virreinales, las elites que se hicieron del poder republicano se ocuparon de modo exitoso de construir nuevas barreras que aseguren que unos y otros se mantuvieran en el lugar social tradicional ${ }^{3}$.

Los grupos que dominaron en la sociedad salteña en el siglo XIX y a comienzos del XX realizaron una operación ideológica a la cual María Fer-

2 El nacionalismo metodológico caracterizó a las teorías sociales de los siglos XIX, XX y XXI, e impregnó la política, la sociedad, la educación, la ciencia. Su rasgo central es la consideración de la sociedad nacional como unidad de análisis. Este supuesto permea y obstaculiza los estudios, además de resultar inútil para el conocimiento de las realidades americanas virreinales tardías y de las tempranas independientes, que exigen una perspectiva analítica de conjunto entre los diferentes espacios que integran la Monarquía hispana.

Sobre el nacionalismo metodológico consúltese: Beck y Sznaider, 2010.

3 Con igualitarismo nos referimos a los distintos dispositivos que tendieron a formar una sociedad igualitaria. La Asamblea del Año 1813 declara a los indios como hombres perfectamente libres e iguales en derecho a los demás ciudadanos, establece la libertad de los hijos de esclavos nacidos después del 31 de enero, suprime los títulos nobiliarios y los distintivos de linajes. 
nanda Justiniano denominó la ideología de la familia tradicional, un decidido trabajo de construcción simbólica y material tendiente a mantener las distancias social e históricamente construidas. Una ideología del poder que vino a instalar nuevas jerarquías y desigualdades en momentos en que las antiguas se desmoronaron ${ }^{4}$.

Juan Antonio Moldes es quizás el mejor ejemplo de esta operación ideológica. Los historiadores salteños fueron los principales responsables de llevar adelante este proceso de invención de capital estatuario. A comienzos del siglo XX, Bernardo Frías en sus célebres Tradiciones históricas de Salta describió a Moldes como perteneciente a las casas nobles de Galicia. A su juicio, habría venido a Buenos Aires ya con la condición de noble desde su tierra natal para asentarse en el Virreinato del Perú. Para el historiador y abogado salteño, Moldes llegó a América junto a su par Pedro Antonio Gurruchaga, a quien también signó de noble, origen vasco y descendientes de cruzados ${ }^{5}$.

Estas primeras aseveraciones, realizadas sin su contrastación con fuentes adecuadas, se mantuvieron sin cuestionarse y se repitieron, en una sociedad republicana que había rechazado en la letra de su Constitución los títulos nobiliarios ${ }^{6}$. Carmen Rosa San Miguel, se refirió al fundador de su familia como un hidalgo gallego, alcalde y regidor del Cabildo, descendiente de los duques de Patiño. Agregó que su tatarabuelo, formó en Salta su hogar con María Fernández de Córdova y Sánchez Loria, de quien expresó, que era descendiente de los primeros conquistadores ${ }^{7}$.

La información se repitió y se repite en las crónicas actuales y en documentos oficiales que divulgan el conocimiento histórico y no pueden desprenderse de estos atavismos ocupados en el sostenimiento de prejuicios racistas y en la creación de héroes del pasado nobiliario, para las nuevas sociedades republicanas ${ }^{8}$.

En una publicación reciente, Marta de la Cuesta y Susana Caro señalan que la sociedad salteña del siglo XVII se caracterizó por su nivel de vida,

4 Justiniano, 2010, cap. 3.

5 Frías, 1924: 213.

${ }^{6}$ La Constitución de la Argentina fue proclamada en 1853. El artículo 16 establece: «La Nación Argentina no admite prerrogativas de sangre, ni de nacimiento: no hay en ella fueros personales ni títulos de nobleza. Todos sus habitantes son iguales ante la ley, y admisibles en los empleos sin otra condición que la idoneidad. La igualdad es la base del impuesto y de las cargas públicas», Constitución de la Nación Argentina, http://servicios.infoleg.gob.ar/infolegInternet/anexos/0-4999/804/norma.htm.

7 San Miguel de Morano, 1999: 37-40.

${ }^{8}$ Las elites locales utilizaron el color de la piel como elemento diferenciador en la sociedad local. Esto se mantiene hasta el día de hoy. Ver Justiniano, 2010. 
elegancia, refinamiento y formación intelectual. En este marco, ubican a los Moldes en el lugar que las autoras denominan primer grupo social, también conocido como «la gente decente» ${ }^{9}$. En tanto, Sara Mata en un artículo publicado en 2012, vuelve a subrayar el origen peninsular de Juan Antonio Moldes. Afirma que poseía a fines de la colonia una de las más importantes casas de comercio de la ciudad de Salta. Destaca su condición de padre de los hermanos Eustaquio, Juan Antonio y José Antonio, que estudiaron, frecuentaban los círculos ilustrados y atendieron los negocios familiares en España, en los años previos a la revolución de $1810^{10}$.

En resumen, la operación ideológica pudo ser exitosa mientras los estudios no superaron los estrechos marcos nacionales. El acceso libre a fuentes globales y una alternativa de análisis relacional permiten exponer un Juan Antonio Moldes diferente, cuyo pasado desconocido, quizás secreto, tal vez oculto, hoy puede desvelarse. A la par emergen, para los estudiosos del pasado, los claros intersticios que los varones de la Monarquía hispánica encontraron y usaron para ubicarse social y económicamente.

Pese a que los territorios americanos habían abierto un abanico de posibilidades, llegar a los virreinatos del Nuevo Mundo no fue una tarea senci1la. Recuérdese que las migraciones hacia estas regiones de la Monarquía no fueron libres. La política regia cuidó que a sus nuevas posesiones arribaran súbditos de la corona, cristianos viejos, varones de ocupación honorable. No alentó durante estos siglos el traslado de un reino a otro allende el Atlántico ${ }^{11}$.

Al momento de testar, el 9 de octubre de 1804, el propio Moldes se presenta y deja en claro su lugar de procedencia y nombres de sus progenitores:

Sea notorio como yo Don Juan Antonio Moldes, vecino y del Comercio de esta Capital, natural de San Pedro de Villalonga Arzobispado de Santiago, Reyno de Galicia, hijo legítimo de Don Plácido Moldes y de Doña Bernarda de Arcaballa y hallándome por la divina misericordia sano y bueno en mi entero y cabal juicio... ${ }^{12}$

Obsérvese que de este modo se cierra una triple operación: ocultar el pasado, encubrir la realidad y crear una nueva identidad. El testamento muestra que al final de la vida, Moldes hubo realizado tales manipulaciones de su historia personal de modo exitoso, ocultó el pasado de criado, lo cubrió con nueva realidad y creó una nueva identidad social.

\footnotetext{
9 De la Cuesta y Caro, 2012.

10 Mata, 2012.

11 Pérez, 2012.

12 Testamento de Juan Antonio Moldes, Biblioteca Atilio Cornejo, Salta, carpeta 8.
} 
Moldes reunió para auto identificarse tres rasgos socialmente valorados de modo positivo por la época: utiliza el tratamiento de Don, se reconoce como vecino y tiene un empleo honorable, pertenece al comercio y es vecino de la plaza local.

Ésta fue la segunda vez, de las que se conocen, que Moldes se presentó así mismo en una documentación requerida por las necesidades y obligaciones de las tramitaciones de la época. La primera vez lo hizo ante la Casa de Contratación, en la península. En realidad, fue Juan Pérez Sánchez quien lo presentó en la solicitud de licencia de embarque para trasladarse él, sus dos criados, y su carga, a Buenos Aires, en la fragata de la Compañía de Sevilla, Señor San Joseph, el 28 de setiembre de $1764^{13}$.

En el documento que aquí se hace referencia, Juan Pérez Sánchez informó en calidad de vecino de la ciudad y de vendedor autorizado por la Real Audiencia:

Digo tengo deliberado pasar del Puerto de la Santísima Trinidad de Buenos Ayres... de los presentes... que se están despachando de la beneficiada a poner cobro a porción de mercaderías que asse de mi propia quenta y riesgo como de la de particulares del Comercio se han cargado en la fragata nombrada San Joseph Limes.

Martín de Olasaval, que esta para hay en viaje a aquel Puerto y me van conmigo en.... Lugar como se acredita de la certificada que dada por la Contaduría Principal de esta Audiencia Real cosa que presente para... manejo de dependencias de viaje y asistencia de mi Persona necesito llevar como compañía dos Criados y por tales propongo a Juan Antonio Moldes natural de San Pedro de Villalonga en Galicia de treinta y dos años de edad de estatura Regular Pelo negro Señal de Henco enel lado izquierdo de la cara; y a Andres Gonzales natural de Sevilla de veinteyocho años de edad Buen cuerpo... de barba y algo tiene de...; los quates son solteros naturales...

Una vez en Buenos Aires, nada sabemos del comerciante arribado desde Cádiz con sus mercaderías y sus dos $\operatorname{criados}^{14}$. En cambio, las fuentes son más pródigas en información para «su criado», Juan Antonio Moldes. Las razones para ello pueden encontrarse en la rápida y exitosa inserción que éste tuvo en la vida americana y los rastros que dejó su profusa actividad social, económica, política, que ayudaron a construir su nueva identidad nobiliaria y ocultar su pasado de criado, puesto en evidencia en la licencia de embarque.

13 Juan Pérez Sánchez, Archivo General de Indias, Sevilla, Contratación, 5507, N.3, R.39 - 1 Recto - Imagen núm. 1. Las negritas son nuestras. Éste documento, al cual puede accederse a través del portal digital PARES, es la primera vez que es considerado para el estudio de la trayectoria de Moldes y/o su descendencia.

14 Lamentablemente en Argentina la digitalización de los archivos históricos es una larga deuda que no se cumple o se cumple muy lentamente. 
Recuérdese que los criados de los territorios de la Monarquía Hispánica procedían de familias con escasos posibilidades económicas. Era justamente la falta de recursos para subsistir una de las razones que movilizó a jóvenes de ambos sexos a dedicarse al servicio doméstico, actividad ésta que era contemplada como poco honorable y que fue el destino de los hijo/as de jornaleros, inquilinos y propietarios agrícolas pobres ${ }^{15}$.

La relación social que se establecía entre criado y amo era vertical y suplió tanto derechos como obligaciones mutuas. El amo tenía el deber de educar, vestir, alimentar y proteger; por su parte las responsabilidades del criado eran múltiples, diversas y varían de acuerdo con la ocasión. En general, se encargaban del servicio doméstico, o acompañar a su señor en la travesía de un viaje durante el cual debía atenderlo. El término «servicio» es, tal vez el que caracteriza de mejor manera las responsabilidades de los criados ${ }^{16}$.

Existió, además, la posibilidad de que los criados aprendieran un oficio. En general éste estuvo en relación con la actividad del amo. Sandra Díaz describe el derrotero de un pretendiente a comerciante. La casa de comercio se convierte en un seminario. Los criados agrupados en grupos de tres o cuatro integrantes, intensifican los vínculos con su amo, reciben instrucciones y aprenden el oficio. Una vez convertidos en maestros podían recibir parte del negocio en la propia casa o podían ser enviados a las Indias ${ }^{17}$.

A mediados del siglo XVIII, en el interior gallego, la hidalguía y el clero secular eran los principales empleadores de criados. Después de estos dos sectores, los administradores y comerciantes fueron los terceros en posicionarse como los grupos con mayor cantidad de criados a sus servicios. En el interior del reino, uno de cada dos criados servía en casa de un miembro de la elite ${ }^{18}$.

La Galicia del siglo XVIII, de la cual fue oriundo Juan Antonio Moldes se caracterizó por su atraso, escasa urbanización, estancamiento económico y limitadas posibilidades de progresar. Aquellos que anhelaban mejorar su calidad de vida, en su mayoría jóvenes de condición exigua, decidían aventurarse hacia tierras más prósperas de la Monarquía ${ }^{19}$.

La América borbónica ofreció muchos incentivos a los españoles peninsulares, tales como disfrute de cargos públicos, posibilidades mercantiles, demanda de oficios especializados. Moldes fue uno de los 55.000 viajeros que

\footnotetext{
15 Gracia Cárcamo, 1995: 110.

16 Goiburu, 2005: 2-15.

17 Díaz de Zappia, 2004: 11.

18 Dubert, 2005: 16.

19 Ibidem: 12.
} 
cruzaron el Atlántico durante el siglo XVIII'20. El número asciende a 120.000 sí son consideradas las salidas legales e ilegales entre 1700 y 1824 desde el puerto de Cádiz ${ }^{21}$. La licencia de embarque otorgada por la Casa de Contratación de Sevilla al comerciante y sus criados no le permitía a ninguno de ellos quedarse, todos debían regresar al cabo de tres años, «en el caso solamente de no despachar sus efectos y sus géneros». Estas disposiciones se encuentran descriptas en los artículos 10 a 14 del Reglamento de Libre Comercio y se mantuvieron vigentes hasta la implosión de la monarquía ${ }^{22}$.

Nada conocemos de cuáles fueron las verdaderas intenciones de Juan Antonio Moldes. Sin embargo, al momento de partir, ya se había movilizado más de $1.000 \mathrm{~km}$ desde su San Pedro de Villalonga natal hasta Cádiz, desde donde embarcó. Una vez en Cádiz, otros 10.000 para cruzar el océano Atlántico y llegar a Buenos Aires, cuando ésta todavía era una ciudad del Virreinato del Perú. No se tienen evidencias que expliquen por qué se trasladó cerca de 1.300 kilómetros para radicarse definitivamente en Salta, y si tenía esta última ciudad como destino final.

Pueden aventurarse algunas hipótesis que expliquen el derrotero seguido y el destino elegido. Una de ellas, la comunidad de paisanos oriundos de Galicia. No solamente para ellos, también para otras nacionalidades estos vínculos fueron fuertes amarras que sostuvieron a los recién $l_{\text {legados }}^{23}$. La propia condición de criado de un comerciante habría brindado las condiciones. A la hora de decidir abandonar la península y su radicación en Salta, Juan Antonio Moldes ya era un hombre maduro, con un oficio e incluso con los vínculos tejidos por su amo. Por último, al momento de decidir su afincamiento, Salta es una urbe en ascenso económico, integrada plenamente a la actividad minera de Potosí, a través de la venta de mulas.

20 Delgado Ribas, 1982: 117.

21 Martínez Shaw, 1994: 165-168.

22 Delgado Ribas, 1982: 121.

23 La documentación genealógica que recopila, conserva y comparte vía internet la organización de genealogía FamilySearch, operada por la Iglesia de Jesucristo de los Santos de los Últimos Días (Iglesia SUD), indica que, al momento de llegar al Río de la Plata, otros gallegos, algunos incluso con el mismo apellido, ya estaban afincados en Montevideo y en Buenos Aires. Sólo a modo de ejemplo, puede citarse a Andrés Moldes, que en 1742 bautizó en la ciudad de Buenos Aires a un homónimo Juan Antonio Moldes. Argentina, Capital Federal, registros parroquiales, 1737-1977, database with images, FamilySearch, https://familysearch.org/ark:/61903/3:1:9396-XR35-RF?cc=1974184\&wc=MDBK-D29\%3A311514201\%2C316597501\%2C316666101, 19 May 2014, Ciudad de Buenos Aires, Nuestra Señora de La Merced, Bautismos 1732-1752, image 286 of 552, parroquias católicas, Buenos Aires (Catholic Church parishes, Buenos Aires). 
Entre las conjeturas debe descartarse el supuesto que Moldes hubiera recurrido a un ardid, promovido su propio desclasamiento, para obtener los permisos requeridos para trasladarse a América. Esto es impensable en una sociedad de antiguo orden por cuanto el estatus nobiliario forma parte de una jerarquía natural dada por Dios.

Salta, al igual que su vecina Jujuy eran parte del camino previo de muchos gallegos para llegar a sus destinos finales, los grandes polos comerciales sudamericanos de Potosí o $\mathrm{Cuzco}^{24}$. A fines del siglo XVIII, el poblado ofrecía grandes posibilidades como centro mercantil articulado a las necesidades de mulas de la actividad minera potosina, para esta época en auge ${ }^{25}$.

\section{Mapa 1. Villalonga en el Reino de Galicia}

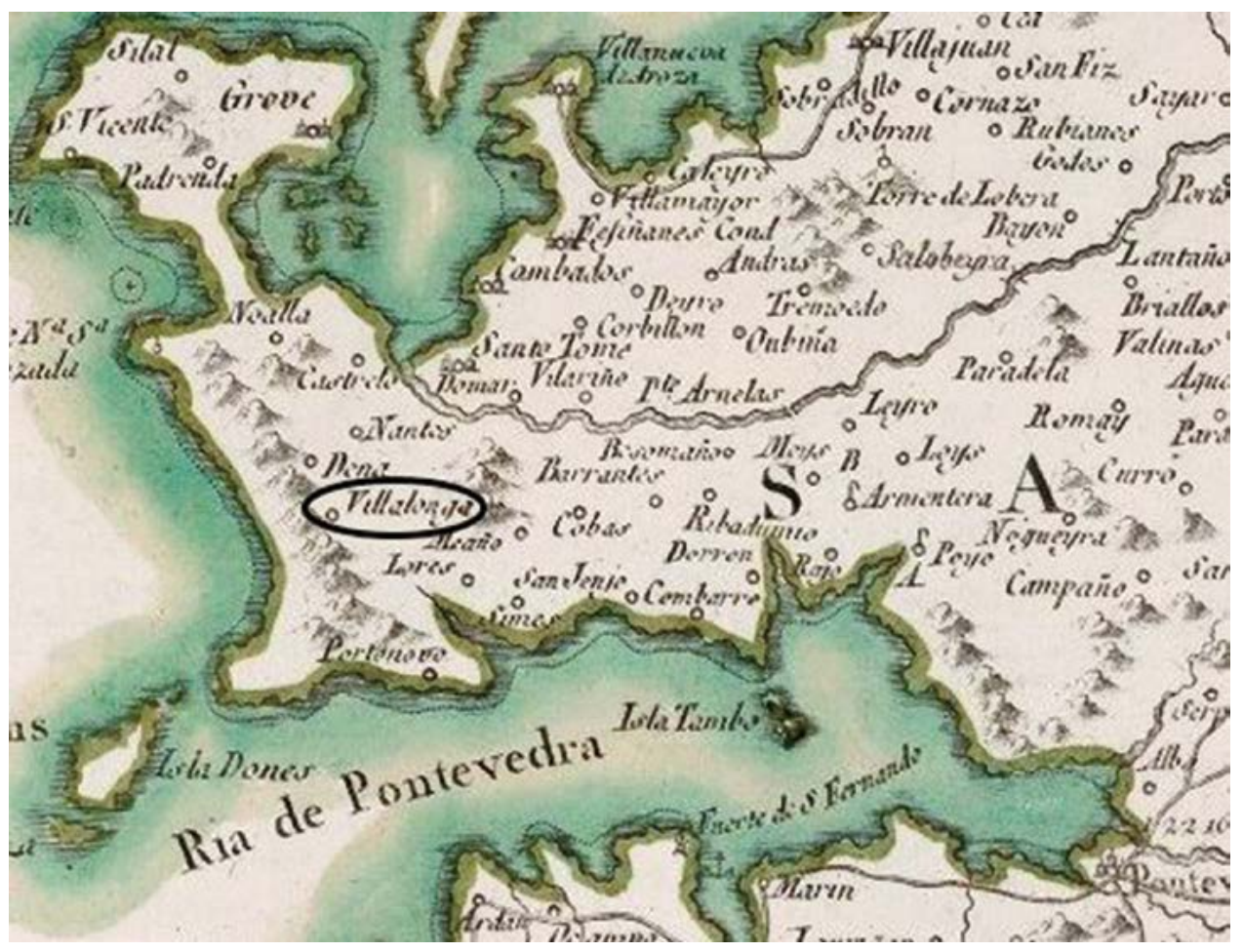

Fuente: López de Vargas Machuca, 1784.

24 De Cristofari, 2009: 125.

25 Bakewell, 2000. 


\section{Mapa 2. Salta en el Tucumán}

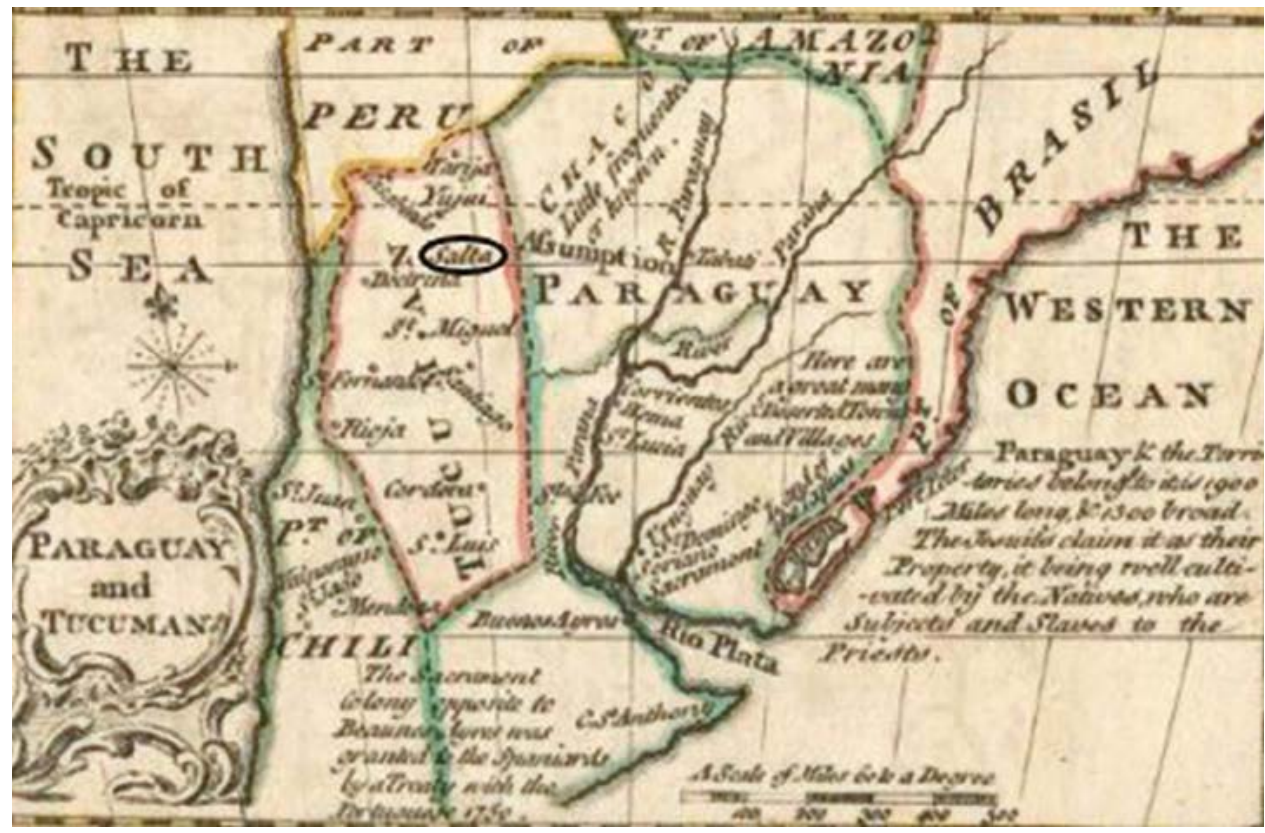

Fuente: Bowen y Gibson, 1758.

Una vez en suelo salteño, el criado gallego siguió las estrategias comunes de los súbditos peninsulares para integrarse con éxito en las sociedades locales. Al igual que Ignacio de Benguria y Joseph Uriburu, ambos peninsulares que también optaron por Salta para radicarse, Moldes eligió a una miembro de las familias que la sociedad local identificaba como «beneméritas» como esposa $^{26}$.

María Antonia Fernández Arias Velázquez fue la elegida. Había nacido en Salta en $1754^{27}$. Su padre fue Manuel Fernández Loria y su madre Antonia Sabina Arias Velázques. Este matrimonio entroncó a Moldes con la familia Arias Velázquez, reconocida como descendiente de los primeros conquistadores afincados en la región ${ }^{28}$.

26 Justiniano, 2008, cap. 2.

27 Argentina, Salta, registros parroquiales, 1634-1972, María Antonia Fernández Arias Velázquez, 1754, images, sitio webb Family History https://familysearch.org/ark:/61903/1:1:XN1FYHH: 22 September 2016.

28 Lloveras y Ontiveros, 2004. 
La dote que aportó María Antonia Fernández a la sociedad matrimonial representó un $10 \%$ del monto de las arras que proveyó el propio Juan Antonio Moldes.

Cuando me case aporte al matrimonio la cantidad de 18.000 y 4 reales de que hice capital según consta del documento respectivo y mi mujer trajo por dote 1716 pesos y tres reales declarándolo para que conste... ${ }^{29}$

El monto de la dote, 1716 pesos, no era representativo de la fortuna de los descendientes de Hernando Arias Velázquez ${ }^{30}$. A modo de comparación en el mismo espacio virreinal, Nora Siegrist encuentra que, en la Buenos Aires del siglo XVIII, las dotes que oscilaron entre más de 4.000 y 6.000 dólares correspondieron a familias adineradas. Muchas veces, no existió en ellas sólo dinero efectivo, también incluyeron casas, campos, haciendas, joyas, bienes muebles, objetos de arte, esclavos, etc. Las dotes que superaron los 12.000 dólares fueron destacables y aquellas que sobrepasaron los 20.000 dólares constituyeron las más ricas de la ciudad porteña ${ }^{31}$.

Ahora bien, a diferencia de la dote, el monto de las arras que entregó Juan Antonio Moldes supera en creces a los aportados en la época. A modo de ejemplo, para consignar casos de principio y de fines del siglo XVIII, el monto de las arras otorgadas por Antonio Arizábal a su prometida Agustina Avellaneda fue de 1.000 pesos, un $10 \%$ de la dote de ésta última, que ascendió a 10.000 pesos, en 1706. En las últimas décadas de la centuria, en 1789, el guipuzcoano Matías Echeverría brindó arras de 600 dólares para su consorte María del Carmen González del Pozo, quien dio en dote 2.330 pesos.

Los ejemplos de arras notablemente inferiores a las dotes se multiplican a lo largo del siglo XVIII. Esta diferencia sustancial entre los montos de la dote de María Antonia y las arras de Juan Antonio Moldes; sumado a que el valor de estas últimas estaba reglado en la décima parte de los bienes del novio, y se fijaba en relación con la calidad de la familia de la novia y su estado civil ${ }^{32}$,

29 Testamento de Juan Antonio Moldes (1804), Biblioteca y Archivo Atilio Cornejo, carpeta 8 , folio 7 .

30 Éste había logrado acceder, como premio de la conquista, a una base económica y de prestigio. Sus sucesores pudieron participar de las esferas de poder, prebendas y privilegios de la sociedad virreinal. De este modo, mantuvieron una posición ventajosa a través de las generaciones e inclusive en las primeras décadas del periodo de emancipación en el siglo XIX (Lloveras y Ontiveros, 2004).

También los descendientes rescatan la fortuna familiar.

31 Siegrist, 2010.

32 Las arras premian la virginidad de la novia. En el caso de que ésta sea viuda, las arras son menores. Ortego Agustín, 1999: 100-102. 
permiten inferir la importancia que le otorgó el futuro marido a la posibilidad social que le ofrecía su consorte.

Tal inversión fue devuelta con creces. Moldes logró insertarse de modo exitoso en la sociedad de la Salta virreinal dieciochesca. A fines de siglo, era un acaudalado comerciante, casado con una miembro de una familia a la que la sociedad de la época reconocía, y se incorporó al grupo de varones que sirvieron al rey. Primero, integró el Cabildo de Salta entre 1785 y 1788 como Alcalde Ordinario de Segundo Voto ${ }^{33}$. Después, en 1791, fue designado Visitador general de la Real Aduana de Salta, cargo que juró el 7 de noviembre ante los miembros del Cabildo de la Ciudad de Salta y el propio Intendente Gobernador Ramón García Pizarro.

Don Juan Antonio Moldes a quien el señor gobernador intendente que ante mí, recibió el juramento que celebro por Dios mío Señor y una señal de cruz bajo el cual prometió de usar fiel y legalmente el cargo de visitador de esta Real Aduana que se le confía y lo afirmo con su señoría de que doy fe... ${ }^{34}$

Queda interrogarse sobre las estrategias que siguió este criado para aportar un capital líquido de 18.000 pesos al momento de casarse y brindar elementos materiales sobre los cuales algunos pudieron construir la operación ideológica descrita en páginas anteriores, de modo tal de ocultar, encubrir y crear una nueva identidad social en los tardíos tiempos virreinales.

\section{DE CRIADO A PRESTAMISTA Y COMERCIANTE GLOBAL}

El derrotero de las estrategias económicas de Juan Antonio Moldes tiene algunos puntos oscuros, en las exposiciones históricas escritas y en las fuentes. Aunque su fortuna es reconocida por sus contemporáneos y los estudiosos actuales de la época, éste no figura en los listados elaborados sobre los hombres acaudalados de la sociedad salteña de la segunda mitad del siglo XVIII. En cuanto a los documentos de su tiempo, no se pudo acceder todavía a fuentes que permitan reconstruir la evolución de su patrimonio, estrategias comerciales desde que llegó a Buenos Aires en 1765, hasta la Tasación de Bienes de 1772 realizada en Salta.

Las exposiciones históricas actuales abocadas al estudio de la elite económica salteña del siglo XVIII no registran el nombre de Juan Antonio Moldes,

33 Lima González Bonorino, 1998.

34 Toma de posesión del cargo de Visitador de la Real Aduana de Juan Antonio Moldes, 1791, Biblioteca Atilio Cornejo, carpeta 5. 
ni en calidad de comerciante ni de propietario rural. Uno de los rasgos de esta historiografía local, que renovó su utillaje teórico y metodológico una vez recuperada la democracia en 1983, es el uso de la categoría analítica de región y el énfasis en la explotación de la tierra como fuente de producción y reproducción de la riqueza y de la elite tardo colonial. El influjo de los aportes de Carlos Sempat Assadourian es otra de las características de los modos de historiar el pasado salteño, en las últimas décadas del siglo XX. Estas perspectivas nutrieron la historiografía colonial, que empezó a abandonar las rígidas demarcaciones nacionales y comenzó definirse como historia colonial andina.

La tabla 1 muestra en dos columnas las principales fortunas de los siglos XVIII y XIX. Tanto en la primera, elaborada por Sara Mata (2000), como la segunda realizada por María Fernanda Justiniano (2010) a partir del Catastro de Propietarios de 1876, está ausente el apellido Moldes. Es decir, no figuran ni Juan Antonio ni su descendencia en el listado de las fortunas de Salta.

En un artículo reciente, Juan Ignacio Quintián también recurre como estrategia investigativa a las posibilidades que brindan los catastros provinciales para identificar a los grandes propietarios salteños entre 1850 y 1880 . Entre los nombres señalados tampoco figura el apellido Moldes ${ }^{35}$.

En resumen, las producciones historiográficas recientes que se proponen indagar sobre la base de la riqueza de la elite salteña en el siglo XIX advierten una discontinuidad entre las grandes fortunas virreinales y las de los tiempos independientes.

La lente creada por Assadourian estimuló encontrar las relaciones económicas y sociales que se establecieron, operaron y se definieron, en un espacio que pasó a ser conceptualizado como espacio peruano; articulado por los polos mercantiles de Lima y Potosí. De este modo, se priorizaron las relaciones inter e intra-regionales, y Salta, sus hombres, sus bienes, pasaron a ser estudiados en su articulación en el espacio peruano y sus vínculos con ambos polos de crecimiento económico, sobre todo con el centro minero de Potosí. Esta preocupación por observar dentro del espacio peruano, no estimuló el estudio ni la búsqueda de relaciones fuera de él.

Sin embargo, Moldes vehiculizó una parte de su fortuna fuera de Salta y de las articulaciones mercantiles en el espacio peruano. El capital que declaró tener al momento de la tasación de sus bienes y de su unión matrimonial con María Antonia Arias Velázquez, está en relación con su actividad de prestamista, y no de comerciante de efectos de Castilla, o productor de efectos de la tierra, o hacendado dedicado a la ganadería mular destinada a Poto-

35 Quitián, 2015. 


\section{Tabla 1. Fortunas de Salta, a FINES De los Siglos XVIII Y XIX}

\begin{tabular}{|l|l|}
\hline Principales fortunas del período 1750-1810* & \multicolumn{1}{|c|}{$\begin{array}{c}\text { Propietarios de las principales casas } \\
\text { de la ciudad capital 1876** }\end{array}$} \\
\hline Isasmendi, Nicolás Severo & Navea, José \\
\hline Martínez de Tineo, Victorino & Aleman de Ortiz, Azucena \\
\hline Arias Rengel, Apolinario & Ojeda, Rosa B. De \\
\hline Arias Rengel, Félix & Ovejero, Sixto \\
\hline Saravia y Aguirre, José & San Miguel, Saturnino \\
\hline Cabrera, José & Patrón Hnos. \\
\hline Aramburu, Nicolás Ignacio & San Miguel, Saturnino \\
\hline Toledo Pimentel, Francisco & Alvarado, Antonia \\
\hline Cornejo, Adrián & Ceballos, Desiderio \\
\hline Carvajal, Ventura & Ceballos, Dolores \\
\hline Arias Velásquez, Baleriano & García, Adolfo \\
\hline López Gregorio & Leguizamón, Juan Galo \\
\hline Aramburu, María Crisóstomo & Lavin, Mariano \\
\hline Castellanos, José Antonio & Ovejero, Querubín \\
\hline Vidart Linares, Juan & Peretti, Santigo \\
\hline Azevedo, Manuel & Zerda, Ángel \\
\hline Arancibia, Lorenzo & Torino, Desiderio \\
\hline Aguirre, Francisco Xavier & Uriburu, José \\
\hline De la Cámara, Juan & Uriburu, Mercedes \\
\hline Rodríguez, Francisco Xavier & Uriburu, Juan Antonio \\
\hline Palavecino, Miguel & López de Celeste Bracchieri \\
\hline Mi, Mateo & Aleman de Ortiz, Azucena \\
\hline & \\
\hline for & $*$ \\
\hline
\end{tabular}

Fuentes: * Mata, 2000: 184. ** Justiniano, 2010, cap. 4. 
sí. Moldes no se dedicó a producir efectos de la tierra, aunque en su testamento manifestó ser propietario de una quinta extramuros.

En 1772, fecha del inventario de bienes citados, Moldes manifestó ante testigos contar con « 48.593 pesos en débitos y existencias a su favor». De este monto, declaró que 18.100 pesos estaban en capital líquido. La fortuna de Moldes de acuerdo con la tasación de 1772 se encontraría entre la tercera más importante de la región, después del Gobernador Intendente Nicolás Severo de Isasmendi y de Victorino Martínez de Tineo, y duplicaría a su pariente político Baleriano Arias Velázquez, quien está enlistado en el onceavo lugar.

El comerciante gallego también integró el listado de los más importantes patrimonios urbanos de la sociedad de la época, pese a que su nombre está ausente de las series elaboradas por los historiadores. Tuvo propiedades urbanas, valuadas en 11.790 pesos. En su testamento manifestó poseer una casa en la calle Del Comercio de la ciudad de Salta, lugar donde residió con su esposa e hijos. Esta vivienda la había comprado en 1774 a José de Saravia y Agustina Castellanos ${ }^{36}$. Al momento de su adquisición ya estaba casado, y había nacido uno de sus hijos, Manuel Benito, y estaba por nacer José Atanasio ${ }^{37}$. Además de esta propiedad, declaró en su testamento tener un solar en un barrio denominado Banda Sur de la ciudad de Salta, una quinta de extramuros, comprada a Francisco Arias en $17799^{38}$.

Moldes es el tercer mayor propietario, ahora de inmuebles en la ciudad, después de Nicolás Severo de Isasmendi y Victorino Toledo Pimentel.

Ahora bien, en disonancia con sus contemporáneos que figuran en las tablas que anteceden Moldes tuvo vínculos comerciales que trascendieron el espacio peruano, articulado por los centros polos mercantiles de Lima y Potosí. Por ejemplo, la relación comercial que mantuvo con Cádiz es reconocida por apologistas e historiadores, pero no es integrada en los análisis.

$\mathrm{Su}$ actividad de prestamista también lo coloca en una situación de discordancia frente al resto de sus coetáneos, dedicados a sus producciones rurales y al comercio regional. Sus deudores más importantes no estaban al Norte sino al Sur, en Buenos Aires; también al Oeste, en Chile. La siguiente tabla

36 Esta casa estuvo en manos de los descendientes de la familia hasta 1930, está ubicada en la calle llamada actualmente Caseros, a la altura del 700, a dos cuadras al Oeste de la plaza principal de la ciudad Salta. Actualmente es una de las cinco únicas casas del siglo XVIII que se conservan (Borelli, Luis, «La historia detrás del fundador del mercado», Diario El Tribuno de Salta, 23 de octubre de 2011).

37 Datos extraídos del sitio web de Family History y del Testamento de Juan Antonio Moldes, 1804, Biblioteca Atilio Cornejo, carpeta 8, folio 19.

38 Testamento de Juan Antonio Moldes, 1804, Biblioteca Atilio Cornejo, carpeta 8, folio 19. 
está elaborada con los datos proporcionados por la tasación de bienes de 1772 y da muestras de esta afirmación.

La tabla 2 detalla el listado de quiénes tienen contraída deudas con Juan Antonio Moldes en Salta. El monto total adeudado por los salteños es de casi 20.000 pesos. Obsérvese que los deudores consignados en la tasación 1772 no se corresponden con los nombres de los principales propietarios de patrimonios urbanos y rurales. Los únicos nombres que se repiten en los listados consignados son los de Pedro Arias y Valeriano Arias.

Los deudores que en la propia tasación son consignados como «obligaciones de Buenos Aires» son menores en número que los salteños, pero adeudan en conjunto un monto mayor. El monto total adeudado por los porteños asciende a 30.000 pesos y supera en creces la cifra de la deuda de los salteños.

A diferencia de los deudores de Salta, muchos de los radicados en Buenos Aires son representativos del mundo mercantil porteño de la segunda mitad del siglo XVIII. Encabeza la tabla Manuel Caviedez, quien al momento de la tasación ya es un comerciante instalado de la plaza porteña, también dedicado al préstamo de dinero y bienes. El segundo de la lista es Manuel Rodríguez de la Vega, de actividad político-comercial en la Ciudad, fue elegido en diferentes oportunidades por sus pares para diversas gestiones, tales como la instalación del Tribunal del Consulado, o manifestar la posición del comercio ante el Virrey. Bernardo Sancho Larrea, quien es tercero en la nómina, también ejerció la actividad mercantil-política. Este último junto a Rodríguez de la Vega participó de la demanda del comercio de la época para la instalación de un consulado en Buenos Aires. Gonzalo Doblas, número doce de la serie de deudores estaba dedicado al préstamo y al comercio de efectos y géneros de castilla. Por último, puede mencionarse a Juan Lezica quien es reconocido como uno de los grandes comerciantes porteños de la época ${ }^{39}$.

La relación con comerciantes de Buenos Aires que se destacaron sea por su giro comercial, sea por su presencia en la vida de la política mercantil, fue un rasgo duradero de las conexiones y relaciones de Juan Antonio Moldes. Al analizar el testamento, que firmó tres años antes de morir en 1807 y 32 años después de la tasación, se encuentra una parte importante de su dinero estaba en manos del comerciante Gerardo Antonio Poze. En el listado proporcionado por el testador, Poze es identificado como un hombre radicado en Buenos Aires. Al igual que los nombrados anteriormente, éste participó en actividades

\footnotetext{
39 Schlez, 2013.
} 


\section{Tabla 2. Deudores salteños de Juan Antonio Moldes, SEGÚN LA TASACIÓN DE 1772}

\begin{tabular}{|c|c|}
\hline Deudores de Salta & Monto en pesos (Reales del ocho) \\
\hline Nicolás Ignasio de Arramburu & 307,00 \\
\hline Juan Alonso Arroyo & 206,00 \\
\hline José Colunga & 336,00 \\
\hline Cristóbal Gordillo y Jacinto Antonio Carro & 216,00 \\
\hline Bernardo Valdez & $1.319,40$ \\
\hline Juan Mojaime & $2.063,30$ \\
\hline Miguel Antonio Aldurralde & 23,70 \\
\hline José Antonio Aldurralde & 324,70 \\
\hline Mateo Salcedo & 0,70 \\
\hline Ramón Antonio Gil Taboada & 160,40 \\
\hline Pedro Montero & 461,00 \\
\hline Antonio Quiroz & 314,20 \\
\hline José Martínez & 300,00 \\
\hline Ignasio Fernández & 38,70 \\
\hline Vicente Jiménez Zisneros & 77,30 \\
\hline Antonio Cornejo & 0,94 \\
\hline Jose Estévez & 303,00 \\
\hline José Javier Dorado & 92,10 \\
\hline Francisco Gavino de Arias & $1.983,20$ \\
\hline Antonio Ruiz Carabajal (Por una escritura) & $9.023,40$ \\
\hline Juan Sandoval & 12,70 \\
\hline José Inojosa & 407,40 \\
\hline Diego Reyes & 0,12 \\
\hline Marcos Velasco & $1.093,00$ \\
\hline Pablo Vidal & 72,30 \\
\hline Valenciano Arias & 14,30 \\
\hline Pedro Arias & 108,30 \\
\hline José Antonio Cruz & 33,60 \\
\hline Monto Total & $19.292,76$ \\
\hline
\end{tabular}

Fuente: Tasación de Bienes de Juan Antonio Moldes de 1772, Biblioteca Atilio Cornejo, Salta, carpeta 8 . 
mercantiles y en demandas políticas para dar solución a problemas que afectaban a su desempeño comercial ${ }^{40}$. Ver tabla 3.

Las cartas mantenidas por Moldes debido a su actividad comercial también muestran esta duradera y sólida relación con los comerciantes de Buenos Aires $^{41}$. Entre los mencionados en la correspondencia por sus relaciones mercantiles se encuentran Tomás Insua y Casimiro Francisco Necochea. El primero fue un destacado comerciante, que ligó su actividad con importantes agentes mercantiles también radicados en Buenos Aires. El segundo, además de su dedicación activa y reconocida a la vida comercial porteña, representó al colectivo mercantil de diferentes modos, entre ellos con el cargo de Apoderado del Consulado de Cádiz en el Río de la Plata. Necochea junto con Juan Anchorena, Martín de Álzaga, Julián de Ugarte, Ezcurra, entre otros estuvieron dedicados a la introducción de grandes cargamentos de ultramar ${ }^{42}$.

Los préstamos otorgados por Juan Antonio Moldes trascendieron las fronteras virreinales y la cordillera. En la tasación de 1772, también figuran como deudores de Juan Antonio Moldes vecinos del «Reino de Chile». Es el caso de Manuel Conchas, quien contrajo una deuda de 300 pesos.

El análisis de la testamentaria de Francisco Javier Sánchez de Lamadrid revela cuán lucrativa fue la actividad de prestamista para Juan Antonio Moldes y cómo esta se sostuvo en el tiempo. En este caso, le prestó al transportista tucumano la suma de por mil pesos plata, que debía ser devuelta al 8\% anual y en seis meses ${ }^{43}$.

Su dinero circuló más allá del Atlántico. En el testamento de 1804 se nombra a Francisco Javier Sanfis, radicado en Cádiz. Éste tuvo en su poder la importante cifra de 13.793,5 pesos de propiedad de Moldes.

El segundo que poseyó dinero de Moldes por su monto fue el mencionado comerciante de Buenos Aires, Gerardo Antonio Poze, y por último su hijo y su yerno, quienes entre ambos reunieron alrededor de 15.500 pesos.

Los intereses de Moldes lo mantuvieron conectado globalmente. Los datos dejan ver el tejido una red mercantil global consolidada a fines del siglo XVIII. Los nodos de la red se distribuyeron en diferentes centros urbanos de la Monarquía, tales como Salta, Buenos Aires, La Paz y Cádiz. Los vínculos establecidos se prolongaron en el tiempo, y se definieron a través de los roles de los agentes, sus intereses y necesidades.

\footnotetext{
40 Schlez, 2013.

41 Correspondencias, Biblioteca Atilio Cornejo, caja 7, carpeta 5.

42 Schlez, 2013.

43 Ávila Sauvage, Parolo y Campi, 2007.
} 
Tabla 3. Deudores de Buenos Aires de Juan Antonio Moldes, Según la TasaCión de 1772

\begin{tabular}{|l|r|}
\hline \multicolumn{1}{|c|}{ Deudores de Buenos Aires } & Monto en pesos (Reales del ocho) \\
\hline Manuel Caviedes & 8.930 \\
\hline Manuel Rodríguez de La Vega & 5.555 \\
\hline Bernardo Sancho Larrea & 4809,5 \\
\hline José Luis Feduche & $1.243,6$ \\
\hline Antonio Miguel Folch & 1.300 \\
\hline Jacobo Felipe Gómez & $1.068,1$ \\
\hline Francisco Balvinos & 500 \\
\hline Vicente Andino & 330 \\
\hline Pedro Seferino San Martin & 166 \\
\hline Juan Mojaime & 734 \\
\hline Manuel Escalada & 795,5 \\
\hline Gonzalo Doblas & 691 \\
\hline Sancho Quiñonez & 323 \\
\hline Juan Lesica & 337,5 \\
\hline Manuel Balvan & 0,94 \\
\hline Saturnino Álvarez & 1,1 \\
\hline Manuel Antonio Tejada & 800 \\
\hline MONTO TOTAL & $\mathbf{2 7 . 8 8 4 , 2 4}$ \\
\hline
\end{tabular}

Fuente: Tasación de los bienes de Juan Antonio Moldes, 1772, Biblioteca Atilio Cornejo, caja 7, carpeta 8. En negritas están señalados los deudores de Buenos Aires reconocidos por su participación en la vida política mercantil porteña.

\section{Tabla 4. Dinero de Juan Antonio Moldes en posesión de terceros}

\begin{tabular}{|l|l|r|}
\hline \multicolumn{1}{|c|}{ Lugar } & \multicolumn{1}{|c|}{ Tercero que posee el dinero } & Monto en pesos (Reales del ocho) \\
\hline Cádiz & Francisco Javier Sanfis & $13.693,5$ \\
\hline Salta & Juan Antonio Moldes (Hijo) & 6.432 \\
\hline Buenos Aires & Gerardo Antonio Poze & 12.500 \\
\hline Salta & Antonio Martinez de San Miguel (Yerno) & $9.193,4$ \\
\hline Monto total & & $\mathbf{4 1 . 9 1 8 , 9}$ \\
\hline
\end{tabular}

Fuente: Testamento de Juan Antonio Moldes, Archivo Biblioteca Atilio Cornejo, caja 7, carpeta 8. 
Al igual que otros hombres de su época fue atraído por Potosí y todo lo que ella irradiaba. Se dedicó al comercio yerba mate cuyo destino final era el centro minero, y a la manufactura de zapatos. Esta última actividad la desplegó en La Paz, actual Bolivia, y tuvo a un africano en condiciones de esclavo dedicado al sostenimiento de la empresa.

El «dinero en manos de terceros» referido en el testamento se correspondió a las sumas que Moldes dejó en individuos de mucha confianza para la realización de transacciones mercantiles. En este caso los nodos de la red estuvieron radicados en las plazas comerciales importantes, como Buenos Aires y Cádiz.

La correspondencia epistolar mencionada en párrafos anteriores también contribuye a desentrañar y conocer mejor los ligámenes que unieron a unos y otros en estas conexiones que superaron los marcos regionales y continentales.

La relación entre Moldes y Francisco Javier Sanfis, radicado en Cádiz, fue de larga duración. Se tiene evidencia de esta afirmación, a través de la correspondencia epistolar y de la testamentaria. Las cartas fueron enviadas desde Cádiz, una en 1796 y otra en 1798. La última constancia del vínculo quedó registrada en la modificación del testamento que realizó Moldes en 1807. Aquí, informa sobre la muerte de Sanfis y la devolución que se hizo del dinero que este tenía en sus manos, a través de la testamentaria del hombre de Cádiz.

Sanfis inicia ambas cartas con tratamientos que hacen referencia a las características del vínculo que lo unió a Moldes: «Paisano y Dueño» y «Muy estimado paisano». La expresión «paisano» da indicio de la procedencia común de ambos. Este tipo de ligamen étnico es una característica de las redes mercantiles construidas en los siglos XVIII y XIX. Carmen Icazuriaga las define como externas ${ }^{44}$. A diferencia del término paisano que se mantiene en ambas misivas, la voz «dueño» sólo se registra en la primera. Su uso brinda elementos que permiten caracterizar el ligamen de asimétrico, rasgo que es refrendado en el cuerpo de las epístolas con tratamientos de respeto como «vuestra merced»y «usted» ${ }^{45}$. La relación de ambos fue netamente comercial. La primera línea del párrafo de la primera carta fue utilizada para informar que el correo que se esperaba no había llegado y la última indica que la relación comercial es previa a la carta. Moldes fue informado que el capital líquido de su cuenta era de 17.809 pesos y 15 reales.

Esta misiva permite conocer agentes comerciales que, integrados a la red, cumplieron el rol de intermediarios (brókeres) con el mundo mercantil porte-

\footnotetext{
44 Icazuriaga, 1979.

45 Sáez Rivera, 2015.
} 
ño. La información brindada también posibilita adentrarse al conocimiento de prácticas comerciales de la época.

En 1796, Sanfís informó a Moldes que éste último le debía 5.000 pesos a Thomas Insua y que de esa deuda había obtenido 6.900 pesos de ganancia líquida, es decir un $138 \%$ de dividendos. La construcción de la deuda, su recorrido y la ganancia recibida fueron relatados por el remitente en el primer párrafo de la carta. El dinero, en realidad, lo dio Insua a cuenta de Casimiro Francisco Necochea. En tanto, Marcos y Vergara fueron los encargados de llevarlo de Buenos Aires a Cádiz.

El segundo párrafo brinda información sobre la función que tuvo Sanfis en la red comercial. Éste estaba encargado de comprar los bienes, acopiarlos y embarcarlos en tiempos propicios hacia América. Al momento de la redacción de la misiva el principal peligro era el conflicto bélico que se acababa de desatar entre las monarquías de Inglaterra y la Hispánica.

En los párrafos siguientes, a la par que se aclara que el tipo de mercancía que remitía Sanfis a Moldes eran géneros «selectos», se obtiene más información sobre la relación comercial de ambos. El remitente identifica dos esferas la de «vuestra merced» y «la nuestra», al momento de decidir no enviar los productos por el riesgo que imponía la guerra.

... no me determino a hacer las remesas algunas ni de cuenta de vuestra merced ni de la nuestra, pues es mejor tener los géneros existentes que aventurarnos a perderlo todo, porque al fin aunque no se gane no se pierde, espero vuestra merced tendrá a bien esta determinación...

La segunda carta fue remitida en 1798. La introducción ha variado notablemente y da muestra de una relación más cercana. El tratamiento es de «Muy estimado paisano». A diferencia de la misiva anterior, antes de brindar la información comercial, Sanfis se mostró satisfecho por las noticias recibidas de Moldes y le informó sobre su estado de salud.

La guerra, que continuó hasta 1802, había hecho imposible la remisión de los bienes desde la Península. A diferencia de la carta anterior, el hombre de Cádiz no expresó la posibilidad de enviar los artículos desde Cádiz por barcos intermediarios o por algún convoy que la Corona destinara expresamente y con protección al Río de la Plata. Al contrario, le informó que el puerto de Cádiz «está bloqueado por veintidós navíos de guerra ingleses, muchas fragatas y los mares cubiertos de corsarios».

Sin embargo, el texto del último párrafo de la misiva de 1798 deja ver que Moldes tuvo otras opciones para la introducción de productos, además de la Península. Ese año esperaba la llegada de géneros desde Filipinas, que Sanfis 
confirmó que no se verificaría por la situación de la guerra: «Los géneros que su merced espera llegasen a Buenos Aires de Filipinas no se verificara».

Esta línea escrita por Sanfis confirma la envergadura relacional construida por Moldes para sus propósitos comerciales y también corrobora aquellas propuestas interpretativas que enfatizan el papel que le cupo a Asia como proveedora de bienes manufacturados en la economía global, antes del ascenso de la economía industrial inglesa ${ }^{46}$. Además, viene a revalidar a quienes advierten el vínculo comercial entre América y Asia, a través del Pacífico, y la conexión por vía del Cabo de Hornos de Filipinas y la Península, una vez creada la Real Compañía de Filipinas en $1785^{47}$.

En el caso de la introducción de productos pretendida por Moldes, nada puede saberse sobre los navíos que estaban previstos para el transporte de los géneros desde Filipinas a Buenos Aires. La redacción se vuelve ilegible y la carta no llega a su fin, pues el papel se encuentra dañado.

\section{A MODO DE CIERRE}

La elite salteña pretendió mantener su posición social tradicional después del tsunami que significaron la implosión de la Monarquía y las guerras de independencia. Para ello, historiadores profesionales, formadores de opinión, apologistas, se dedicaron a construir las barreras sociales y los principios diferenciadores. Entre ellos, paradójicamente, el linaje adquirió una inusitada importancia en la flamante vida republicana que demandaba en los textos constitucionales la igualdad de los ciudadanos.

Pronto los grupos dirigentes decimonónicos salteños se vieron entroncados con las casas nobiliarias europeas. El caso de Juan Antonio Moldes se convierte en un notable ejemplo de esta operación ideológica, que pretendió mantener las distancias del antiguo régimen en el nuevo orden independiente. Moldes pudo ocultar su pasado de criado, encubrir sus orígenes y generarse un linaje nobiliario que después acentuarán los biógrafos.

A más de doscientos años, la consulta de nuevas fuentes, y la perspectiva analítica global y relacional de análisis permiten restituir un Moldes de mayor interés para la historiografía regional y para la historia. Su trayectoria de vida, las formas de lograr prestigio y fortuna social, a la vez que ratifica la acertada estrategia del matrimonio con descendientes de las fami-

46 Entre las principales líneas interpretativas, puede señalarse a: Frank, 2009: 95-140. Flynn y Dennis, 1995. Pomeranz, 2000. Bonialian, 2012.

47 Bonialian, 2012. Díaz-Trechuelo, 2003. 
lias consideradas beneméritas; obliga a considerar que la construcción de riqueza en la sociedad salteña tardo virreinal también estuvo asociada a actividades económicas propias de la esfera de la circulación, como el comercio y el préstamo.

La trayectoria de prestamista también arroja luz sobre un espacio de acción de estos comerciantes salteños, que excede el articulado por el polo potosino. Se vuelca desde temprano hacia el Atlántico, vinculándose con comerciantes porteños y de Cádiz.

Por último, el papel del Pacífico. Aunque, la correspondencia epistolar existente es exigua, deja ver que a fines del siglo XVIII la introducción de productos manufacturados por vía de Filipinas constituía una opción ante el descalabro de las comunicaciones por la guerra.

Moldes, a la luz de la información recogida, es un caso notable de ascenso social en la monarquía hispana. Un hombre que siguió las estrategias establecidas para poder ubicarse socialmente y poder hacer una de las fortunas más importantes de su entorno. El préstamo y el comercio de ultramar fueron la base de su riqueza. Este rédito mercantil estuvo anclado en una red de envergadura global que se desplegó por América, España y Asia.

Al final de su vida, no sólo es rico sino también funcionario de una monarquía que entró implosión inmediatamente después de su muerte.

\section{BiBLIOGRAFÍA}

Ávila Sauvage, Verónica, Parolo, María Paula y Campi, Daniel, "Hacendados y comerciantes. Actores económicos y estrategias de inversión en la jurisdicción de San Miguel de Tucumán a fines del Siglo XVIII", XIV Congreso de Historia Agraria, Badajoz, 2013, http://seha.info/congresos/articulos/CD3.\%20\%C3\%81vila,\%20Parolo\%20y\%20Campi.pdf.

Bakewell, Peter, "La minería Hispanoamericana colonial", Leslie Bethell (ed.), Historia de América Latina. Tomo II. América Latina Colonial: Europa y América en los siglos XVI, XVII y XVIII, Barcelona, Editorial Crítica, 2000.

Beck, Ulrich y Sznaider, Natan, "Unpacking cosmopolitanism for the social sciences: a research agenda", The British Journal of Sociology, 61 (Londres, 2010): 381403, doi:10.1111/j.1468-4446.2009.01250. x.

Bonialian, Mariano, El Pacífico hispanoamericano: política y comercio asiático en el Imperio Español (1680-1784), México, El Colegio de México, 2012.

Bowen, Emanuel y Gibson, John, Paraguay and Tucuman, Londres, Newberry, 1758, disponible en https://www.davidrumsey.com/luna/servlet/detail/RUMSEY 8 1 239 218 5511692:Paraguay-and-Tucuman. 
De Cristofari, Nadia Andrea, Proa al Plata: las migraciones de gallegos y asturianos a Buenos Aires (fines del siglo XVIII y comienzos del XIX), Madrid, CSIC, 2009.

De la Cuesta, Marta y Caro, Susana, "Sociedad y Cultura en tiempos de Güemes", Boletín del Instituto Güemesiano de Salta, 37 (Salta, 2012): 56-67.

Delgado Ribas, Josep M., "La emigración española a América Latina durante la época del comercio libre (1765-1820). El ejemplo catalán", Boletín Americanista, 32 (Barcelona, 1982): 115-137.

Díaz de Zappia, Sandra L., "Pervivencia de los criados en la Hispanoamérica del siglo XVIII: el Río de la Plata", Temas de Historia Argentina y Americana, Buenos Aires, Facultad de Filosofía y Letras, 2004, tomo IV.

Díaz-Trechuelo, Lourdes, "La Real Compañía de Filipinas en Guipúzcoa", Revista de Estudios Marítimos del País Vasco, 4 (Barcelona, 2003): 369-381.

Dubert, Isidro, "Criados, estructura económica y social y mercado de trabajo en la Galicia rural a finales del Antiguo Régimen", Historia agraria: Revista de agricultura e historia rural, 35 (Zaragoza, 2005): 9-26.

Dubert, Isidro, "Ilegitimidad, matrimonio y mercados de trabajo femeninos en la Galicia interior, 1570-1899", Obradoiro De Historia Moderna, 24 (Santiago de Compostela, 2015): 49-86, doi:10.15304/ohm.24.2827.

Flynn, Dennis y Giráldez, Arturo, “Born with a 'Silver Spoon': The Origin of World Trade in 1571" Journal of World History, 6/2 (Honolulu, 1995): 201-221.

Frank, André Gunder, "ReOriente. Economía global en la Era Asiática. Conclusiones", Crítica y Emancipación, 2 (Buenos Aires, 2009): 95-140.

Frías, Bernardo, Tradiciones Históricas, Buenos Aires, Jesús Menéndez, 1924.

Gracia Cárcamo, Juan Antonio, "La condición social de los sirvientes y los conflictos económicos con sus patronos en Vizcaya (siglos XVIII y XIX)", Vasconia: Cuadernos de historia - geografia, 23 (Donostia-San Sebastián, 1995): 105-135.

Goiburu, Irene Alicia, Las interacciones sociales entre amos y criados en América Colonial: traspaso del medioevo europeo, Rosario, Universidad Nacional de Rosario, 2005, http://cdsa.aacademica.org/000-006/96.pdf.

Icazuriaga, Carmen, "Españoles de Veracruz y vascos del Distrito Federal: su ubicación en la estructura económica de México", Michael Kenny, Carmen Icazuriaga, Virginia García, Clara Elena Suárez y Gloria Antis, Inmigrantes y refugiados españoles en México (siglo XX), México, Ediciones de La casa chata, 1979.

Justiniano, María Fernanda, La elite salteña (1880-1916). Estrategias familiares y evolución patrimonial, tesis de doctorado, La Plata, Universidad Nacional de La Plata, Facultad de Humanidades y Ciencias de la Educación, 2008, http://www. memoria.fahce.unlp.edu.ar/tesis/te.728/te.728.pdf.

Justiniano, María Fernanda, Entramados del poder. Salta y la Nación en el siglo XIX, Quilmes, UNQUI, 2010. 
Justiniano, María Fernanda, Aportes de las perspectivas relacional y global a la historiografía de los tiempos modernos, Buenos Aires, Universidad de Buenos Aires, 2012, https://www.academia.edu/8068394/Aportes_de_las_perspectivas_relacional_y_global_a_la_historiograf\%C 3\%ADa_de_los_tiempos_modernos.

Justiniano, María Fernanda, "Ser o no ser, el dilema del Estado moderno en la exposición histórica escrita actual", Guillermo Nieva Ocampo, Rubén González Cuerva y Andrea Navarro, El príncipe, la corte y sus reinos. Agentes y prácticas de gobierno en el mundo hispano, XIV-XVIII, Tucumán, Humanitas, 2016: 421-437.

Lima González Bonorino, Jorge F., La primitiva sociedad colonial en la provincia de Salta, Buenos Aires, Dunken, 1998.

Lloveras de Arce, Graciela y Ontiveros, Daniel Medardo, "Estudio de dos familias de élite en salta durante el período colonial: el caso de los Arias Velázquez y Arias Rengel”, Revista Escuela de Historia (2004), http://www.rehunsa.com/revista0209. htm.

López de Vargas Machuca, Tomás, 52. Mapa geográfico del Reyno de Galicia, Madrid, Calle de Atocha frente a la Plazuela, 1784, disponible en: https://davidrumsey.georeferencer.com/maps/571034034329/.

Martínez Shaw, Carlos, La emigración española a América (1492-1824), Colombre, Archivos Indianos, 1994.

Mata, Sara, "El crédito mercantil. Salta finales del siglo XVIII", Anuario de estudios americanos, 53/2 (Sevilla, 1996): 147-171.

Mata, Sara, Tierra y poder en Salta. El Noroeste argentino en vísperas de la independencia, Sevilla, Diputación de Sevilla, 2000.

Mata, Sara, "La herencia de la guerra: Salta (Argentina) 1821-1831", Nuevo Mundo. Mundos Nuevos, [en línea], Debates, Puesto en línea el 11 julio 2012, consultado el 09 julio 2019, http://journals.openedition.org/nuevomundo/63221, doi: 10.4000/ nuevomundo.63221.

Ortego Agustín, María Ángeles, Familia y matrimonio en la España del Siglo XVIII: Ordenamiento jurídico y situación real de las mujeres a través de la documentación notarial, tesis doctoral, Madrid, Universidad Complutense de Madrid, 1999.

Pérez, Mariana Alicia, "Introducción al dossier: De Europa al Nuevo Mundo: la inmigración europea en Iberoamérica entre la Colonia tardía y la Independencia", Nuevo Mundo Mundos Nuevos, [en línea], Debates, Puesto en línea el 18 junio 2012, consultado el 09 julio 2019, http://journals.openedition.org/nuevomundo/63251.

Pomeranz, Kenneth, The Great Divergence. China, Europe and the Making of the Modern World Economy, Princeton, Princeton University Press, 2000.

Quitián, Juan Ignacio, "Características económicas y sociales de la elite salteña (1850-1880)", Americanía. Revista de Estudios Latinoamericanos, Nueva Época, Número Especial (Sevilla, 2015): 270-299. 
Sáez Rivera, Daniel, “El secretario español de Carlos Pellicer como protopragmática", Études Romano de Brno, Brno, Faculty of Arts, Masaryk University, 2015: 119-148.

San Miguel de Morano, Carmen, Mi niñez, La Plata, Mediacalgraf, 1999.

Schlez, Mariano Martín, Los circuitos comerciales tardo-coloniales. El caso de un comerciante monopolista: Diego de Agüero (1770-1820), tesis doctoral, Buenos Aires, Universidad de Buenos Aires, 2013.

Siegrist, Nora, "Dotes matrimoniales en Buenos Aires en épocas del Antiguo Régimen. Siglos XVII al XVIII", Naveg@mérica. Revista electrónica de la Asociación Española de Americanistas, 4 (2010): 2.

Fecha de recepción: 5 de junio de 2017.

Fecha de envío de las modificaciones: 3 de septiembre de 2017.

Fecha de aceptación: 5 de septiembre de 2017.

\section{Juan Antonio Moldes: from servant to global trader and royal official (Salta, Buenos Aires, Cádiz, Philippines, 1764-1804)}

Opinion makers and social scholars favoured the construction of differentiating principles in the brand-new independent society of Salta. Global and relational approaches provide theoretical and methodological tools that allow us to overcome the interpretative limits of methodological nationalism loaded with Eurocentric assumptions.

This article aims to deconstruct this ideological operation and, through the study of Juan Antonio Moldes, to show the social mobility possible under the Hispanic Monarchy and in the Intendance of Salta del Tucumán.

Loan activities and the construction of a commercial network of global level, which included Salta, Buenos Aires, Cadiz, the Philippines, La Paz, Potosi enabled Moldes, a Galician servant, to make money and advance socially, politically and economically in the society that gave him protection.

KEY WORDS: economic history; history of Argentina; regional history; history of Salta. 